\title{
Generation of an index for physiological imbalance and its use as a predictor of primary disease in dairy cows during early lactation
}

\author{
K. M. Moyes, ${ }^{1}$ T. Larsen, and K. L. Ingvartsen ${ }^{2}$ \\ Department of Animal Science, Faculty of Science and Technology, Aarhus University, DK-8830 Tjele, Denmark
}

\begin{abstract}
Physiological imbalance (PI) is a situation in which physiological parameters deviate from the normal and cows consequently have an increased risk of developing production diseases and reduced production or reproduction. The objectives of this work were (1) to generate an index for PI based on several plasma metabolites and (2) to compare the use of this index with calculated energy balance (EBAL) and individual plasma metabolites in relation to risk of disease during early lactation. We used a total of 634 lactations from 317 cows consisting of 3 breeds ranging from a parity of 1 to 4 . Weekly blood samples were analyzed for selected metabolites; that is, urea nitrogen, albumin, cholesterol, nonesterified fatty acids (NEFA), glucose, and $\beta$-hydroxybutyrate (BHBA). Energy intake and EBAL were calculated; veterinary treatment records and daily composite milk somatic cell counts were used to determine incidence of disease. Data were adjusted for numerous fixed effects (e.g., parity, breed, and week around calving) before further statistical analysis. The time of disease (TOD) was recorded as the day in which the signs of disease were observed $(\mathrm{TOD}=0)$. The week before and after TOD was $\pm \mathrm{n}$ wk relative to TOD $=$ 0 . Each week, all plasma metabolites were individually adjusted to an overall mean $(=0)$ and variance $(=1)$. The normalized variables were included in regression analyses by week of lactation to identify metabolites that explain the variation in calculated EBAL, as a reflection of degree of PI. Nonesterified fatty acids, BHBA, and glucose were weighted within each week based on regression coefficients (i.e., $\mathrm{x}_{1}-\mathrm{x}_{3}$ below) generated from a model to predict EBAL. Data from wk -1 relative to TOD were analyzed using a mixed linear model to relate degree of PI and metabolites in blood to risk of disease. The weekly PI index was defined as PI $=\left(\mathrm{x}_{1} \times[\mathrm{NEFA}]\right)+\mathrm{x}_{2} \times[\mathrm{BHBA}]-\mathrm{x}_{3} \times[$ glucose $\left.]\right) / 3$.
\end{abstract}

Received April 20, 2012.

Accepted December 9, 2012.

${ }^{1}$ Current address: Department of Animal and Avian Sciences, University of Maryland, College Park 20742.

${ }^{2}$ Corresponding author: KlausL.Ingvartsen@agrsci.dk
For diseases that developed $\geq 2$ wk after calving, no variables were associated with risk of disease. Prepartal PI and plasma NEFA were better predictors of disease (i.e., metritis, retained placenta, and milk fever) at wk 1 than EBAL and plasma BHBA and glucose. Examining the relationship between PI and milk constituents is needed for the development of an automated in-line and real-time surveillance system for early detection of risk animals on-farm.

Key words: cow, physiological imbalance, disease

\section{INTRODUCTION}

Due to improvements in genetic selection programs and management over the past few decades, the amount of milk produced per cow per year has steadily increased; however, disease incidence is still substantial, especially in early lactation (Ingvartsen, 2006; Heikkilä et al., 2012). The dairy industry has undergone significant structural changes by which the number of cows per farm has increased, thereby increasing the number of cows being managed per herd personnel. Thus, the need for automated surveillance systems for in-line and real-time measurements for early detection of cows at risk for disease on-farm has increased. The use of surveillance will allow farmers to implement management strategies to prevent disease, improve animal health and welfare, reproduction, and production, and thereby increase economic outcome.

The transition period is a critical time in the life cycle of the dairy cow, characterized by major changes (e.g., in the endocrine, immune, and digestive systems) during which cows are at a greater risk for disease than any other time period. We hypothesized that reducing the degree of physiological imbalance (PI) in individual cows - defined as cows whose physiological parameters deviate from normal and who, consequently, have increased risk of developing production diseases (clinical or subclinical) and reduced production or reproduction (Ingvartsen, 2006) - will reduce the risk of disease and, thereby, improve production and reproductive performance (Ingvartsen, 2006; Moyes et al., 2010). For decades, researchers have used calculated energy balance (EBAL), primarily based on DMI, milk yield, and milk 
components, as the gold standard to reflect the degree of change in energy mobilization during early lactation in relation to risk of disease. Studies have shown that calculated negative EBAL, and the metabolites that characterize negative EBAL, are associated with reduced fertility (Walsh et al., 2011), immune function and increased risk of some infectious (Ingvartsen et al., 2003; Loor et al., 2011) and noninfectious diseases (Ingvartsen, 2006; Huzzey et al., 2011). We hypothesize that an index for PI, based on several metabolites in blood, will more directly relate to mechanisms associated with the development of several diseases during early lactation and, in turn, will be a better predictor of risk of disease than, for example, standard methods used to calculate EBAL described previously (National Research Council, 2001; Friggens et al., 2007) or the use of individual metabolites alone.

The development of such an index is dependent on the degree of biological understanding of PI. Several reviews (Ingvartsen et al., 2003; Ingvartsen, 2006; LeBlanc, 2010) identified plasma NEFA, BHBA, and glucose as the major metabolites that relate to degree of PI. Recently, we quantified the individual animal response to dietary-induced PI via changes in nutrient supply at different stages of lactation and production levels. We identified plasma NEFA, BHBA, and glucose as the major metabolites that relate to the degree of PI during early lactation (Bjerre-Harpøth et al., 2012). However, evaluating the benefits of including other variables in blood (e.g., BUN and cholesterol) in the index for PI to improve the use of PI as a risk factor for disease is warranted.

We have previously reported that the size of the between-animal variation may vary through the lactation cycle and is large in early lactation for cow traits such as plasma NEFA and BHBA (Ingvartsen and Friggens, 2005). For this study, we generated the individual between-cow variation (defined as random) in a mixed model that included relevant fixed effects and observed that the individual between-cow variation was quite substantial (Ingvartsen and Friggens, 2005). Understanding the natural basis for this individual variation and describing this variation in relation to PI and the risk of disease may lead to new management strategies that prevent and reduce the incidence of diseases and reproduction or production problems at the level of individual animals. The objectives of this study are to use the individual between-cow variation to (1) generate an index for naturally occurring PI based on several plasma metabolites using a large-scale study and (2) compare the use of this index with calculated EBAL and individual plasma metabolites in relation to risk of both infectious and noninfectious diseases for individual cows during early lactation.

\section{MATERIALS AND METHODS}

Data for this study originated from a large experiment that included 634 lactations within 317 cows ranging from a parity of 1 through 4 at the farm Ammitsbøl Skovgaard, Egtved, Denmark. Descriptions of animals used, experimental design, and data collection were previously provided (Nielsen et al., 2003; Ingvartsen and Friggens, 2005; Moyes et al., 2009b). Briefly, data were collected from January 1996 to October 2001 from cows of 3 breeds - Danish Red $(n=104)$, Danish Holstein $(\mathrm{n}=130)$, and Jersey $(\mathrm{n}=83)$-throughout their entire productive lives. Only data collected from -4 through 9 wk relative to parturition were used for this study (i.e., when cows are at the greatest risk for $\mathrm{PI})$.

\section{Production Variables}

Milk Yield and Milk Composition. Cows were milked twice daily between 0600 and $0800 \mathrm{~h}$ and then again between 1600 and $1800 \mathrm{~h}$. At each milking, milk yield was measured (Milk Meter, SAC, Kolding, Denmark) and fat, protein, lactose, and SCC (1,000 cells/ $\mathrm{mL}$ ) were analyzed using a CombiFoss 4000 (Foss Electric, Hillerød, Denmark). Energy-corrected milk was calculated as described by Sjaunja et al. (1990) using milk yield and milk composition.

Blood and Tissue Collection. Blood samples were collected via puncture of the jugular vein in the morning weekly from wk -4 through 9 relative to parturition. Additional blood samples were collected at d 1, 3, and 7 after parturition and a weekly average for each variable was calculated; for further details on blood sampling see Ingvartsen and Friggens (2005). Plasma samples were analyzed for NEFA, BUN, cholesterol, triglycerides (TAG), glucose, albumin, BHBA, and insulin according to methods described by Mashek et al. (2001). Liver tissue was collected at wk 1 and 3 after parturition and analyzed for total lipid, TAG, and glycogen content (Andersen et al., 2002).

Calculation of Energy Balance. Energy balance was calculated based on the following equation for body energy change (EBody) from feed energy input (EFeed) and the energy requirements for milk (EMilk), lean tissue growth (EGrowth), conceptus growth (EConceptus), maintenance (EMaintenance), and activity (EActivity):

$$
\begin{aligned}
\text { EBody }= & \text { EFeed }-(\text { EMilk }+ \text { EGrowth }+ \text { EConceptus } \\
& + \text { EMaintenance }+ \text { EActivity }) .
\end{aligned}
$$

Details of the individual calculations for the equation components are described elsewhere (Friggens et al., 
2007). A standard adjustment was made for EActivity in part because (1) the animals were housed in tie-stalls, and therefore variation was low, and (2) measurement of the variation between animals in this quantity was not possible.

\section{Definition of Disease}

Disease. Cows were classified as developing clinical signs of milk fever, retained placenta (RP), dystocia, metritis, left displacement of the abomasum (LDA), lameness, rumen acidosis, uterine prolapse, pneumonia, and ketosis based on veterinary observations and treatment records. As blood calcium concentration was not evaluated at the time of disease, milk fever cases were assumed to be typical or classical. Cows were classified into disease types based on the first signs of disease observed during lactation (i.e., primary disease). Therefore, diseases that developed as a secondary problem were not used for this study (e.g., secondary ketosis or LDA associated with reduced feed intake relating to a primary disease). Cows classified as "other" developed diseases such as rumen acidosis, pneumonia, and uterine prolapse. In this study, the methods of Moyes et al. (2009b) were followed, with minor modifications, for cows that remained healthy or developed sub-clinical or clinical mastitis. Briefly, cows that did not display any signs of clinical disease were not treated for any disease throughout the first 9 wk of lactation. Cows that had daily composite SCC $<500,000$ cells/mL during the first week of lactation and milk SCC $<100,000$ cells $/ \mathrm{mL}$ throughout the first 9 wk of lactation were classified as healthy. Diagnoses for cows that developed clinical mastitis were based on daily composite SCC and veterinary treatment records obtained throughout the first $9 \mathrm{wk}$ of lactation. Cows classified as developing sub-clinical mastitis were not used for this study.

Time of Disease. The time of disease (TOD) was recorded following methods described by Moyes et al. (2009b). Briefly, the DIM in which either the first initial increase in daily composite SCC was observed (clinical mastitis only) or the first clinical signs of disease were observed was recorded as TOD $=0$. As blood was collected on a weekly basis, the time after and before TOD were designated as $\pm \mathrm{n}$ wk relative to $\mathrm{TOD}=0$. Cows that developed a disease in early lactation were paired with a healthy cow based on breed and parity. The TOD for each healthy cow was equal to the TOD for their respective pair.

Frequency Distributions. The majority of diseases occurred during the first week of lactation and, therefore, the data were separated into 2 parts: cows that developed disease during wk 1 of lactation (WEEK1), and cows that developed disease during wk 2 to 9 of
Table 1. Frequency distributions for cows that did or did not develop disease during wk 1 (WEEK1; i.e., 0-7 DIM) or during wk 2 through 9 of lactation (EARLYLACT)

\begin{tabular}{lcc}
\hline Disease & WEEK1 $^{1}$ & EARLYLACT \\
\hline Retained placenta & $59(62)$ & - \\
Milk fever & $33(36)$ & - \\
Dystocia & $7(7)$ & - \\
Left displaced abomasum & $3(3)$ & - \\
Metritis & $10(10)$ & $13(13)$ \\
Lameness & $6(6)$ & $2(2)$ \\
Ketosis $^{2}$ & - & $10(10)$ \\
Other $^{2}$ & $16(16)$ & $24(24)$ \\
Hlinical mastitis $^{3}$ & $69(69)$ & $113(145)$ \\
Toalthy $^{5}$ & $113(145)$ & $160(206)$ \\
\hline Cows $^{4}$ & $279(391)$ &
\end{tabular}

${ }^{1}$ Cows (lactations).

${ }^{2}$ Other $=$ rumen acidosis, uterine prolapse, and pneumonia.

${ }^{3}$ Clinical mastitis $=$ for both WEEK1 and EARLYLACT, cows treated for clinical mastitis and had daily composite milk SCC $\geq 800,000$ cells/ $\mathrm{mL}$.

${ }^{4}$ Healthy $=$ cows that were not treated for and did not show any clinical signs of disease at any time during the early lactation, had daily composite milk SCC $\leq 500,000$ cells $/ \mathrm{mL}$ within the first week of lactation, and daily composite milk SCC did not increase above 100,000 cells $/ \mathrm{mL}$ for $\geq 3$ consecutive days during wk 2 through 9 of lactation.

${ }^{5}$ Total $=$ total number of cows that were classified into WEEK1 and EARLYLACT. Total does not reflect the sum of individual diseases as several cows may have been classified as healthy in one lactation and diseased in a subsequent lactation.

lactation (EARLYLACT). The final data set used to relate degree of PI to risk of disease included a total of 350 lactations from 240 cows from WEEK1 and 194 lactations from 148 cows for EARLYLACT (Table 1).

\section{Statistical Analysis}

Estimation of Between-Cow Variation. All blood variables, except plasma glucose, albumin, cholesterol, and BUN, were natural log-transformed before statistical analysis. The first step of the analysis was to estimate the between-cow variation for each variable. The between-cow variation (random effect) was calculated in a mixed model where the fixed effects of breed, parity, genetic selection line within breed, assay, diet, calving date, days dry, DIM, year, and season, as well as the relevant interactions between these effects, was estimated using the univariate REML procedure of SAS version 9.2 (SAS Institute Inc., 2008) as described elsewhere (Ingvartsen and Friggens, 2005). Therefore, the variables included in the index for PI will be independent from above systemic effects known to cause variation in the variables of interest - only the betweencow differences (variance) remained. The between-cow variance was then used for further analysis.

Generation of PI Index. For each week, EBAL, energy intake, average daily milk yield, and all variables in plasma were adjusted to an overall mean $(=0)$ and a 
variance $(=1)$. Regression analyses (PROC GLM) were used to identify blood variables that explain the majority of change in calculated EBAL. Calculated EBAL was used as the gold standard reflecting changes in PI; the regressions were run by week. Most variation was explained by changes in NEFA and glucose during early lactation. Because of its high biological association with disease during early lactation (Nielsen et al., 2005), BHBA was also included in the final model. The final linear model, run by week, was:

$$
\begin{aligned}
\mathrm{Y}_{i}=\beta_{0} & +\mathrm{x}_{1} \times \mathrm{NEFA}_{i}+\mathrm{x}_{2} \times \mathrm{BHBA}_{i} \\
& -\mathrm{x}_{3} \times \text { glucose }_{i}+\mathrm{e}_{i},
\end{aligned}
$$

where $Y_{i}=$ EBAL for the $i$ th cow; $\beta_{0}=$ the $y$-intercept; $\mathrm{x}_{1-3}=$ the regression coefficients for NEFA, BHBA, and glucose, respectively; $\mathrm{NEFA}_{i}=$ concentration of NEFA for the $i$ th cow; $\mathrm{BHBA}_{i}=$ concentration of BHBA for the $i$ th cow; glucose ${ }_{i}=$ concentration of glucose for the $i$ th cow; and $\mathrm{e}_{i}=$ the unexplained variation for the $i$ th cow. The Type III sums of squares were used to determine whether or not these effects were significant.

Subsequently, parameters for each variable (metabolite) were weighted at each week relative to the absolute value of the regression coefficients generated from the model above. For each metabolite, the weight (i.e., coefficient below) at each week was adjusted to \% relative to 100 , allowing for discussion of the relative importance of the metabolites in explaining EBAL. The final PI index is as follows:

$$
\begin{gathered}
\mathrm{PI}=\left(\mathrm{x}_{1} \times[\mathrm{NEFA}]+\mathrm{x}_{2} \times[\mathrm{BHBA}]\right. \\
\left.-\mathrm{x}_{3} \times[\text { glucose }]\right) / 3 .
\end{gathered}
$$

where $\mathrm{x}_{1}, \mathrm{x}_{2}$, and $\mathrm{x}_{3}$ represent the adjusted weights for NEFA, BHBA, and glucose estimated from the regression coefficients generated from the regression analysis above.

PI Index and Risk of Disease. Pearson correlations were used to generate correlations between the PI index and other parameters over time. To determine how disease was linked to degree of PI, EBAL, and individual metabolites, data were analyzed using the MIXED procedure with a random effect of cow within pair. As only 3 cows developed LDA and 2 cows developed primary ketosis, cows were grouped into the disease category of "other" for WEEK1 and EARLYLACT, respectively. The model was run by disease. Fixed effects included cow and disease and the model included disease. Data were analyzed at wk -1 relative to the development of disease (i.e., TOD $=-1$ ) to associate changes in PI with early risk of disease during early lactation. To compare the value of each variable as an indicator of disease risk, the standardized difference (SDiff) was calculated for each variable within each disease as follows: $\left(\mathrm{LSM}_{\text {Yes }}-\mathrm{LSM}_{\mathrm{No}}\right) / \mathrm{SEM}$.

\section{RESULTS AND DISCUSSION}

The fixed effects in EBAL and selected metabolites normally observed during the transition period have been eliminated to allow for more generalized use of the between animal variation in physiological variables for this study. This means that all weekly physiological and production data are presented as differences from zero (i.e., average after adjustments for fixed effects). Ingvartsen and Friggens (2005) observed substantial between-cow variations after adjustments for fixed effects which raised the question: How does this variation relate to degree of PI and risk of diseases? This study is the first to generate an index for PI based on betweencow variations in several metabolites in blood and to examine how degree of PI relates to risk of disease for individual cows in early lactation when compared with other known indicators of metabolic status (i.e., plasma NEFA, BHBA, glucose, and calculated EBAL).

Table 2 shows the regression coefficient estimates, standard error, and probability that the regression coefficient deviates from zero for plasma NEFA, glucose, and BHBA, as well as information for the regression model selected to predict degree of PI based on between-cow variations in calculated EBAL within wk -4 to 9 relative to parturition. The model only explained $\leq 6 \%$ of the between-cow variation in EBAL $\left(\mathrm{R}^{2}\right)$ in wk -4 to -1 before calving. During wk 1 , the $\mathrm{R}^{2}$ increased to $14 \%$ with a maximum of $17 \%$ in wk 2 ; thereafter it declined to $12 \%$ in wk 9 . As the data for each variable is normalized $($ mean $=0$, variance $=1)$, then the relative size of the regression coefficients in Table 1 indicate the relative importance of each variable at a given week. During the prepartal period, the results indicate that NEFA concentration is the most important variable followed by BHBA, whereas glucose does not seem to be very important. During the postpartal period, NEFA was again the most important parameter, with glucose being almost as important as NEFA, whereas BHBA is of minor importance for the first $6 \mathrm{wk}$ of lactation. To illustrate the relative importance of the metabolites in explaining calculated EBAL over time, the regression coefficients for each metabolite (Table 2) were then weighted for each week and presented in Figure 1. Glucose concentration partly explained variations in EBAL in the early lactation period only, whereas BHBA explained variations in EBAL during wk -4 to -2 prepartum $(P<0.10)$ and not until wk 7 postpar- 
tum. Between-cow variations in NEFA explained up to $\sim 80 \%$ of the described variation in EBAL at wk -1 . After calving, glucose explained $\sim 33 \%$ of the described variation in EBAL by wk 1 of lactation. As lactation progressed, the contribution of BHBA gradually increased; and by $\sim$ wk 7 of lactation, all 3 metabolites were weighted similarly for explaining variations in EBAL. These results on naturally occurring variation in physiological variables support recent work in our laboratory where plasma NEFA, BHBA, and glucose had the greatest change in concentration when compared with other metabolites during dietary-induced PI for cows in early lactation (Bjerre-Harpøth et al., 2012). This is further supported by Sigl et al. (2012), where changes in circulating concentrations of NEFA, BHBA, and glucose were observed for cows in early lactation. For cows in later lactation, marked changes in plasma BHBA are minimal during periods of feed restriction (Moyes et al., 2009a); indicating that the conversion of acetyl-CoA to ketone bodies is minimal, and the capacity for complete hepatic $\beta$-oxidation of FA is sufficient when compared with cows in early lactation (Drackley, 1999). Our results suggest that prediction for ketosis early in lactation may be as dependent on changes in plasma glucose level as BHBA for individual cows in early lactation. However, only 2 cows developed primary ketosis in early lactation for this study and additional large-scale studies examining the use of plasma glucose in combination with BHBA as a predictor of ketosis are warranted.

Figure 2 shows weekly Pearson correlations between degree of PI and calculated EBAL, milk yield, energy

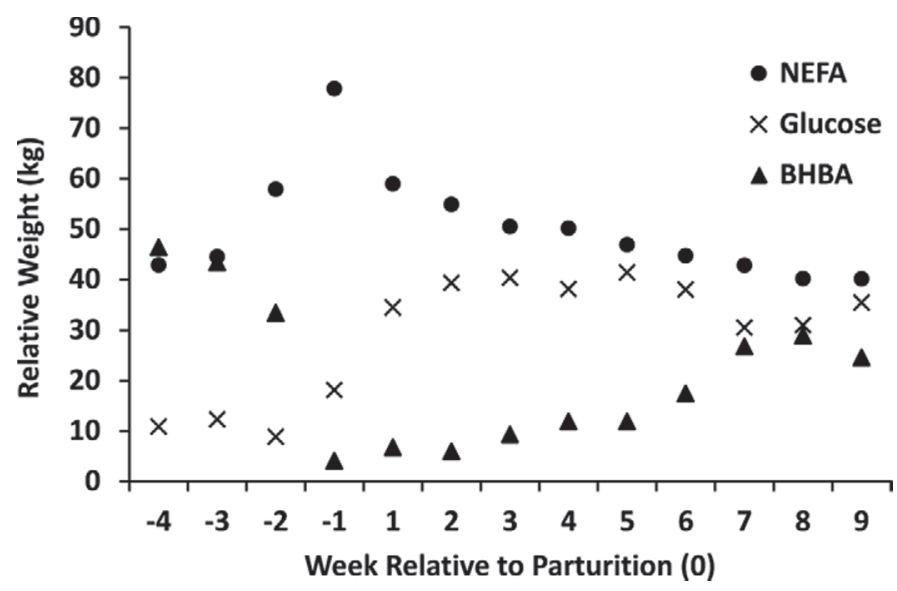

Figure 1. Weights for selected metabolites to be included in the model to predict calculated energy balance. Metabolites were weighted at each week via the absolute value of the estimates generated from the regression model in Table 2. For each metabolite, the weight at each week was adjusted to percentage relative to 100 .

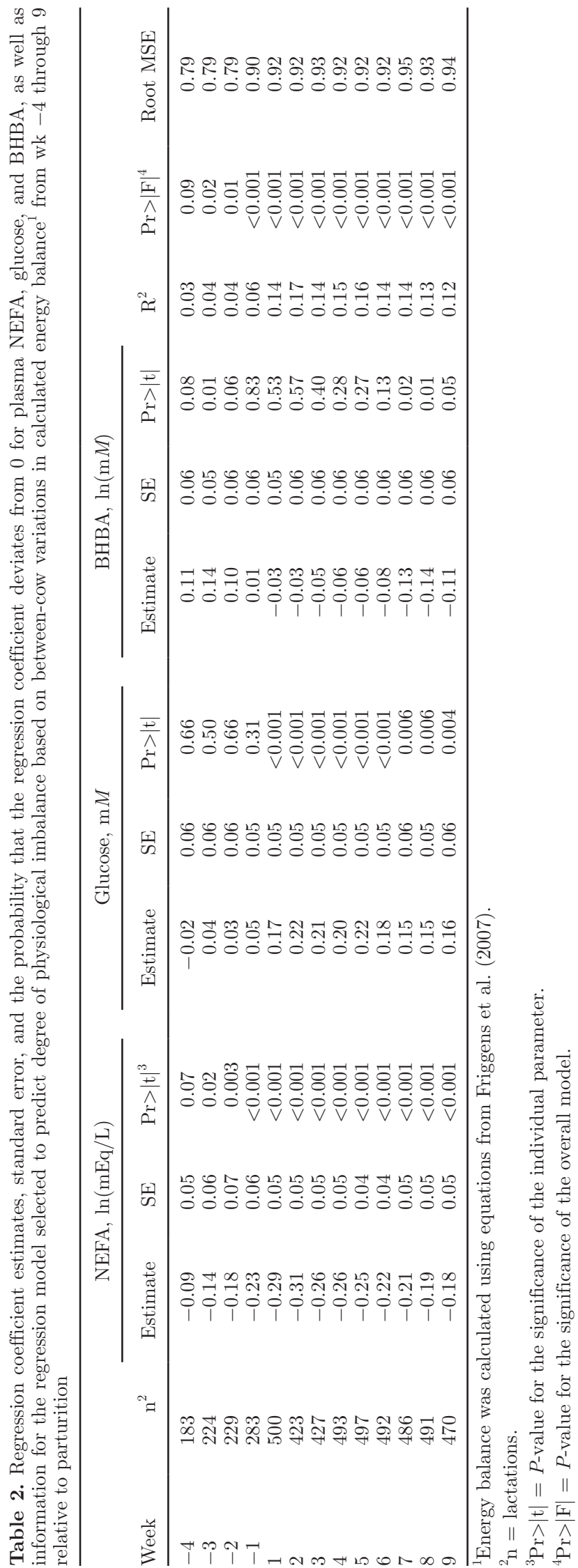

Journal of Dairy Science Vol. 96 No. 4, 2013 


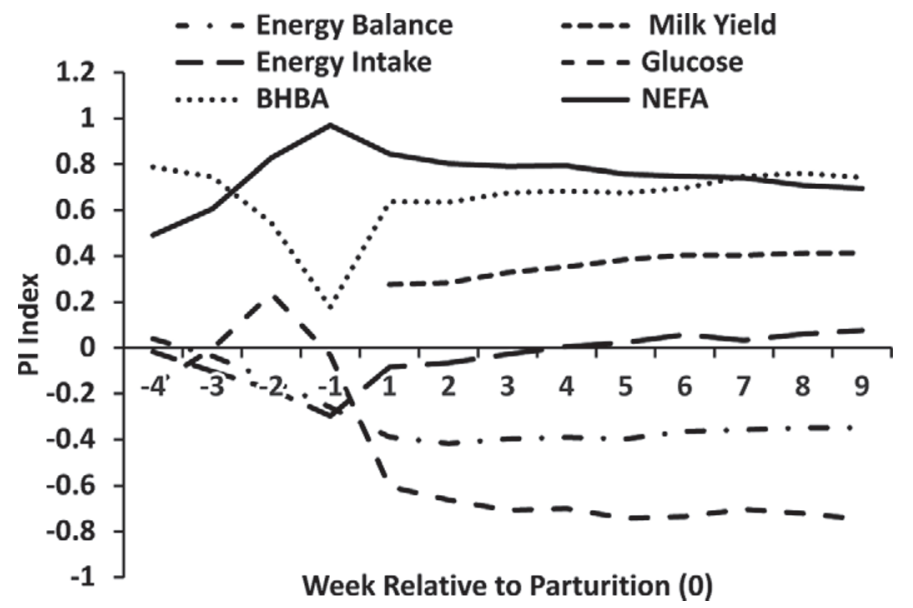

Figure 2. Weekly Pearson correlations between degree of physiological imbalance (PI), and calculated energy balance, milk yield, energy intake, or plasma NEFA, BHBA, and glucose for cows from -4 to 9 wk relative to parturition.

intake, or plasma NEFA, BHBA, and glucose for cows from -4 to 9 wk relative to parturition. A weak negative correlation was observed between energy intake and PI at $-2(\mathrm{r}=-0.10 ; P=0.04)$ and $-1 \mathrm{wk}(\mathrm{r}=-0.24 ; P$ $<0.001)$ relative to parturition. This supports Ingvartsen and Andersen (2000), who argued that the natural dip in feed intake around calving is, at least partly, due to the mobilization of lipid. During the postpartal period, however, energy intake was not correlated with degree of PI, indicating that degree of naturally occurring PI is independent from energy intake postpartum. During dietary-induced PI, degree of PI was negatively correlated to changes in DMI for cows in early, mid, and late lactation indicating that PI may be a useful indicator of off-feed situations throughout lactation (Bjerre-Harpøth et al., 2012).

After parturition, a weak negative correlation between degree of PI and EBAL was observed, whereas a moderate to strong negative correlation was observed between plasma concentration of glucose and PI. For plasma concentration of NEFA and BHBA, a strong positive correlation with PI was observed during early lactation, whereas milk yield was only weakly correlated to milk yield (Figure 2). Higher yielding cows generally tend to mobilize greater amounts of adipose tissue energy, resulting in greater changes in plasma NEFA, BHBA, and glucose, which increased the risk of disease during early lactation. However, milk yield does not seem to be a good predictor for PI based on our recent work showing a negative correlation between milk yield and dietary-induced PI (Bjerre-Harpøth et al., 2012); therefore, changes in milk yield may be a consequence of off-feed situations. Degree of PI was moderately correlated with total lipid $(\mathrm{r}=0.39 ; P<0.001)$, TAG $(\mathrm{r}=$ $0.40 ; P<0.001)$, and glycogen $(\mathrm{r}=-0.38 ; P<0.001)$ content in the liver at wk 1 postpartum, with similar patterns observed at wk 3 postpartum. This provides support for the use of the PI index as a predictor of metabolic function or status of the liver associated with the uptake, utilization, and secretion of lipids by the liver. Results warrant further investigation examining the use of the PI index as a potential indicator for risk of disease (e.g., hepatic lipidosis during early lactation).

For EARLYLACT cows, the estimated between-cow variations in $\mathrm{PI}$ index and between-cow differences in calculated EBAL, plasma NEFA, BHBA, and glucose were not related to the development of disease during early lactation. Table 3 shows the variations in PI, EBAL, and plasma concentration of NEFA, BHBA, and glucose at wk -1 relative to development of metritis, $\mathrm{RP}$, or milk fever for WEEK1 cows. None of the variables for WEEK1 or EARLYLACT cows were different between cows classified as developing "other" diseases (i.e., rumen acidosis, LDA, and ketosis) when compared with healthy cows. Cows with a higher PI index at wk -1 before parturition had a greater risk of metritis $(P$ $<0.001)$, RP $(P<0.05)$, and milk fever $(P<0.05)$ at calving than cows with a lower PI index. Calculated EBAL and BHBA at wk -1 before parturition were not good indicators $(P>0.05)$ for risk of metritis, RP, and dystocia (data not shown) at parturition. However, prepartal EBAL was higher $(P<0.05)$ for cows that developed milk fever, and prepartal BHBA tended $(P$ $=0.08)$ to be higher when compared with healthy cows. Prepartal NEFA was higher for cows that developed metritis $(P<0.001)$, RP $(P<0.001)$, and milk fever $(P<0.05)$ than healthy cows. Prepartal glucose was lower for cows with metritis $(P<0.05)$ and dystocia $(P$ $<0.01$; data not shown), whereas cows that developed milk fever had higher $(P<0.01)$ glucose when compared with healthy cows.

The estimated between-cow variations in PI, EBAL, and plasma concentrations of NEFA, BHBA, and glucose at wk -1 relative to parturition for all diseases, lameness, or mastitis for WEEK1 cows are shown in Table 4. Degree of PI was greater for cows with lameness $(P<0.05)$ and mastitis $(P<0.01)$. In general, cows classified as developing a disease (i.e., all diseases) had a greater $(P<0.01)$ degree of PI than healthy cows. Similar to Table 3, EBAL and BHBA were not good indicators of diseases for either WEEK1 or EARLYLACT cows. For all diseases for WEEK1 cows, NEFA and glucose were higher for diseased than healthy cows at wk -1 before parturition. Glucose and NEFA were higher for cows that developed clinical mastitis for WEEK1 
Table 3. Least square means, SEM, ${ }^{1}$ and the standardized differences (SDiff) ${ }^{2}$ for estimated between-cow variations in physiological imbalance (PI), ${ }^{3}$ calculated energy balance (EBAL), and plasma concentration of NEFA, BHBA, and glucose at wk -1 relative to development of metritis, retained placenta, or milk fever during the first wk after parturition (WEEK1)

\begin{tabular}{|c|c|c|c|c|c|c|c|c|c|c|c|c|c|c|c|}
\hline \multirow[b]{3}{*}{ Variable } & \multicolumn{15}{|c|}{ Disease } \\
\hline & \multicolumn{5}{|c|}{ Metritis } & \multicolumn{5}{|c|}{ Retained placenta/dystocia } & \multicolumn{5}{|c|}{ Milk fever } \\
\hline & Yes $^{5}$ & No & SEM & $P$-value & SDiff & Yes & No & SEM & $P$-value & SDiff & Yes & No & SEM & $P$-value & SDiff \\
\hline PI & 18.3 & -3.1 & 5.1 & $<0.001$ & 4.2 & 2.7 & -3.1 & 2.4 & 0.04 & 2.4 & 3.7 & -3.1 & 3.0 & 0.04 & 2.3 \\
\hline EBAL & -7.6 & -1.1 & 6.9 & 0.36 & -0.94 & -2.4 & -1.1 & 2.8 & 0.68 & -0.46 & 7.5 & -1.1 & 3.7 & 0.03 & 2.3 \\
\hline NEFA & 0.17 & -0.02 & 0.05 & $<0.001$ & 3.8 & 0.06 & -0.02 & 0.03 & $<0.001$ & 2.7 & 0.06 & -0.02 & 0.03 & 0.02 & 2.7 \\
\hline BHBA & 0.03 & -0.01 & 0.03 & 0.20 & 1.3 & -0.02 & -0.01 & 0.01 & 0.36 & -1.0 & -0.02 & -0.01 & 0.02 & 0.22 & -0.5 \\
\hline Glucose & -0.08 & -0.01 & 0.03 & 0.03 & -2.3 & -0.01 & -0.01 & 0.01 & 0.48 & 0.0 & 0.04 & -0.01 & 0.02 & $<0.01$ & 2.5 \\
\hline
\end{tabular}

${ }^{\mathrm{I}} \mathrm{SEM}=$ the largest SEM within a disease is shown.

${ }^{2}$ Standardized differences $=($ Yes - No) $/$ SEM

${ }^{3} \mathrm{PI}=\left(\mathrm{x}_{1} \times[\mathrm{NEFA}]+\mathrm{x}_{2} \times[\mathrm{BHBA}]-\mathrm{x}_{3} \times[\right.$ glucose $\left.]\right) / 3$, where $\mathrm{x}_{1-3}=$ coefficients generated by regression analysis.

${ }^{4} \mathrm{EBAL}$ was calculated using equations from Friggens et al. (2007).

${ }^{5}$ Yes $=$ cows that developed clinical disease; no = cows that did not develop any disease (i.e. healthy).

Table 4. Least square means, SEM, ${ }^{1}$ and the standardized differences (SDiff) ${ }^{2}$ for estimated between-cow variations in physiological imbalance (PI) ${ }^{3}$ calculated energy balance (EBAL), ${ }^{4}$ and plasma concentration of NEFA, BHBA, and glucose at wk -1 relative to development of all diseases, ${ }^{5}$ lameness, or mastitis during either the first wk after parturition (WEEK1)

\begin{tabular}{|c|c|c|c|c|c|c|c|c|c|c|c|c|c|c|c|}
\hline \multirow[b]{3}{*}{ Variable } & \multicolumn{15}{|c|}{ Disease } \\
\hline & \multicolumn{5}{|c|}{ All Diseases ${ }^{5}$} & \multicolumn{5}{|c|}{ Lameness } & \multicolumn{5}{|c|}{ Mastitis } \\
\hline & $\mathrm{Yes}^{6}$ & No & SEM & $P$-value & SDiff4 & Yes & No & SEM & $P$-value & SDiff & Yes & No & SEM & $P$-value & SDiff \\
\hline PI & 2.6 & -3.1 & 1.5 & $<0.01$ & 3.8 & 1.3 & -3.1 & 6.8 & 0.05 & 0.65 & 3.2 & -3.1 & 2.0 & $<0.01$ & 3.2 \\
\hline EBAL & 0.91 & -1.1 & 1.6 & 0.38 & 1.6 & -7.2 & -1.1 & 8.8 & 0.49 & -0.69 & 1.7 & -1.1 & 2.7 & 0.38 & 1.0 \\
\hline NEFA & 0.05 & -0.02 & 0.01 & $<0.001$ & 7.0 & 0.08 & -0.02 & 0.07 & 0.17 & 1.4 & 0.06 & -0.02 & 0.02 & $<0.001$ & 4.0 \\
\hline BHBA & 0.001 & -0.01 & 0.01 & 0.47 & 1.1 & 0.005 & -0.005 & 0.03 & 0.75 & 0.33 & 0.009 & -0.005 & 0.01 & 0.24 & 1.4 \\
\hline Glucose & 0.01 & -0.01 & 0.01 & 0.01 & 2.0 & 0.09 & -0.01 & 0.04 & 0.01 & 2.5 & 0.04 & -0.01 & 0.01 & $<0.001$ & 5.0 \\
\hline
\end{tabular}

${ }^{1}$ SEM $=$ the largest SEM within a disease is shown.

ळ $\quad{ }^{2}$ Standardized difference $=($ Yes - No $) /$ SEM.

$\subseteq{ }^{3} \mathrm{PI}=\left(\mathrm{x}_{1} \times[\mathrm{NEFA}]+\mathrm{x}_{2} \times[\mathrm{BHBA}]-\mathrm{x}_{3} \times[\right.$ glucose $\left.]\right) / 3$, where $\mathrm{x}_{1-3}=$ coefficients generated by regression analysis.

$\& \quad{ }^{4} \mathrm{EBAL}$ was calculated using equations from Friggens et al. (2007).

$z \quad{ }^{5}$ All diseases $=$ the total number of diseases reported in Table 1 for WEEK1 cows.

$\quad{ }^{6}$ Yes $=$ cows that developed clinical disease; No $=$ cows that did not develop any disease (i.e., healthy). 
cow than healthy cows. Only prepartum PI and glucose were higher for cows that developed lameness at wk 1 .

To compare the value of each variable as an indicator for risk of disease during early lactation, the statistical significance (i.e., $P$-value) in combination with the SDiff was used. The SDiff was higher for PI and plasma NEFA for most diseases, especially all diseases (Table 4), and suggests that changes in PI and plasma NEFA are better predictors of disease risk than EBAL, plasma BHBA, and glucose after parturition. Our results show that an index for PI, based on plasma NEFA, BHBA, and glucose, relates to risk for most diseases and supports the growing evidence linking overall metabolic status to risk of infectious (Ingvartsen et al., 2003; Loor et al., 2011; Ingvartsen and Moyes, 2012) and noninfectious diseases (Ingvartsen, 2006; Huzzey et al., 2011) in dairy cows. The study showed that prepartal degree of PI was linked to disease after calving. Calculated EBAL failed to predict the risk of disease during early lactation, except milk fever. This contradicts previous studies showing relationships between severity of peripartal EBAL status and incidence of certain diseases during early lactation (Drackley, 1999). However, higher prepartum NEFA was also associated with incidence of diseases such as metritis, milk fever, mastitis, and $\mathrm{RP}$, and supports the growing evidence relating plasma NEFA to risk of disease during the peripartal period (Ingvartsen, 2006; LeBlanc, 2010; Seifi et al., 2011; Ingvartsen and Moyes, 2012). Interestingly, prepartal BHBA was not associated with the incidence of any disease after parturition and does not support previous studies showing evidence of increased risk for diseases (e.g., metritis and RP) for cows with greater concentrations circulating BHBA during early lactation (Ingvartsen, 2006; LeBlanc, 2010; Ospina et al., 2010). Our results indicate that prepartal NEFA concentration is a better indicator of risk for disease than glucose and BHBA. Ospina et al. (2010) reported similar results, where postpartum NEFA was more associated with the development of diseases (e.g., metritis, RP) when compared with BHBA. In the present study, NEFA contributed the most when PI was parameterized using EBAL as the golden standard and, coupled with results of Ospina et al. (2010), suggests that changes in NEFA are significantly better at reflecting metabolic status and risk of disease than BHBA and glucose.

Besides prepartal NEFA, lower prepartal glucose was associated with increased incidence of most diseases. However, higher prepartal glucose was associated with increased incidence of lameness, mastitis, and milk fever, whereas lower prepartal glucose was associated with metritis and dystocia. Results confirm our previous findings, where greater plasma NEFA and glucose prepartum were observed for cows that developed clinical mastitis after calving (Moyes et al., 2009b). To our knowledge, our results are the first to show relationships between prepartal glucose and the incidence of diseases such as lameness, metritis, and milk fever. The inverse relationship between prepartal glucose and risk of some diseases needs further investigation. In general, our results show that glucose is more closely related to risk of disease than changes in BHBA. However, cows that developed diseases after calving experienced higher prepartal NEFA, suggesting insulin resistance for cows that develop diseases during the early postpartal period. Upon further investigation, prepartal concentration of insulin in plasma was similar $(P>$ $0.10)$ and the glucose:insulin ratio tended $(P=0.07)$ to be greater for diseased and healthy cows after calving (data not shown). Our results suggest a lower efficiency of glucose clearance from circulation for cows that develop diseases after calving (Moyes et al., 2009b). Previous studies have shown links between higher prepartal NEFA in plasma and increased insulin resistance during the postpartal period (Vernon, 2005; Schoenberg et al., 2011; Schoenberg and Overton, 2011). The relationship between prepartal metabolism and insulin resistance is not fully understood. Our results suggest a potential link between insulin resistance and increased risk of disease during early lactation.

Few studies have shown relationships between circulating concentration of glucose and the risk of disease during early lactation. Sakha et al. (2007) reported lower serum glucose concentrations for cows with sub-clinical ketosis than healthy cows, whereas other researchers observed no association between glucose in blood and risk of disease (i.e., LDA and ketosis) and culling during the postpartal period (Stengärde et al., 2010; Seifi et al., 2011). In the present study, the development of sub-clinical diseases was not evaluated and the incidence of LDA and clinical ketosis was low due to our strict focus on the development of primary diseases during early lactation (i.e., not the development of a disease as a secondary health problem). Future studies investigating the use of the PI index and individual metabolites as predictors of sub-clinical disease is needed. In addition, the use of between-cow variations (i.e., adjustments for several fixed effects known to cause variations in metabolites; Ingvartsen and Friggens, 2005), may partly explain some of the associations between metabolic status and the risk of disease during early lactation.

\section{CONCLUSIONS}

This study is the first to generate an index for PI based on weighted concentrations of between-cow 
variations in NEFA, BHBA, and glucose in blood during the periparturient period. None of the measured variables related to risk of disease for EARLYLACT cows. Results clearly demonstrated that cows with higher PI prepartum were at a greater risk for developing diseases (i.e., mastitis, metritis, RP), milk fever, and lameness after calving. Higher prepartal NEFA and glucose were significantly associated with risk of certain diseases after parturition. The PI index and plasma NEFA were better predictors of disease when compared with calculated EBAL and plasma glucose and BHBA. Future studies examining the use of the relationship between degree of PI index and milk constituents are needed for the development of automated in-line and real-time surveillance systems for early detection of "at risk" animals on-farm. An automated system onfarm will improve surveillance and help farmers carry out proactive risk management to prevent disease and improve dairy cow welfare, reproduction, productivity, and economic outcome.

\section{ACKNOWLEDGMENTS}

This work was supported by the Danish National Advanced Technology Foundation (Copenhagen, Denmark), Lattec I/S (Hillerød, Denmark), The Milk Levy Fund (Copenhagen, Denmark), and the Danish Ministry of Food, Agriculture and Fisheries (Copenhagen, Denmark).

\section{REFERENCES}

Andersen, J. B., D. G. Mashek, T. Larsen, M. O. Nielsen, and K. L. Ingvartsen. 2002. Effects of hyperinsulinaemia under euglycaemic condition on liver fat metabolism in dairy cows in early and midlactation. J. Vet. Med. A Physiol. Pathol. Clin. Med. 49:65-71.

Bjerre-Harpøth, V., N. C. Friggens, V. M. Thorup, T. Larsen, B. M. Damgaard, K. L. Ingvartsen, and K. M. Moyes. 2012. Metabolic and production profiles of dairy cows in response to decreased nutrient density to increase physiological imbalance at different stages of lactation. J. Dairy Sci. 95:2362-2380.

Drackley, J. K. 1999. Biology of dairy cows during the transition period: The final frontier? J. Dairy Sci. 82:2259-2273.

Friggens, N. C., P. Berg, P. Theilgaard, I. R. Korsgaard, K. L. Ingvartsen, P. Lovendahl, and J. Jensen. 2007. Breed and parity effects on energy balance profiles through lactation: Evidence of genetically driven body energy change. J. Dairy Sci. 90:5291-5305.

Heikkilä, A. M., J. I. Nousiainen, and S. Pyorala. 2012. Costs of clinical mastitis with special reference to premature culling. J. Dairy Sci. 95:139-150.

Huzzey, J. M., D. V. Nydam, R. J. Grant, and T. R. Overton. 2011. Associations of prepartum plasma cortisol, haptoglobin, fecal cortisol metabolites, and nonesterified fatty acids with postpartum health status in Holstein dairy cows. J. Dairy Sci. 94:5878-5889.

Ingvartsen, K. L. 2006. Feeding- and management-related diseases in the transition cow, physiological adaptions around calving and strategies to reduce feeding-related diseases. Anim. Feed Sci. Technol. 126:175-213.

Ingvartsen, K. L., and J. B. Andersen. 2000. Integration of metabolism and intake regulation: A review focusing on periparturient animals. J. Dairy Sci. 83:1573-1597.
Ingvartsen, K. L., R. J. Dewhurst, and N. C. Friggens. 2003. On the relationship between lactational performance and health: Is it yield or metabolic imbalance that cause production diseases in dairy cattle? A position paper. Livest. Prod. Sci. 83:277-308.

Ingvartsen, K. L., and N. C. Friggens. 2005. To what extent do variabilities in hormones, metabolites and energy intake explain variability in milk yield? Domest. Anim. Endocrinol. 29:294-304.

Ingvartsen, K. L., and K. M. Moyes. 2012. Nutrition, immune function and health of dairy cattle. Animal http://dx.doi.org/10.1017/ S175173111200170X

LeBlanc, S. 2010. Monitoring metabolic health of dairy cattle in the transition period. J. Reprod. Dev. 56(Suppl.):S29-S35.

Loor, J. J., K. M. Moyes, and M. Bionaz. 2011. Functional adaptations of the transcriptome to mastitis-causing pathogens: The mammary gland and beyond. J. Mammary Gland Biol. Neoplasia $16: 305-322$.

Mashek, D. G., K. L. Ingvartsen, J. B. Andersen, M. Vestergaard, and T. Larsen. 2001. Effects of a four-day hyperinsulinemic-euglycemic clamp in early and mid-lactation dairy cows on plasma concentrations of metabolites, hormones, and binding proteins. Domest. Anim. Endocrinol. 21:169-185.

Moyes, K. M., J. K. Drackley, J. L. Salak-Johnson, D. E. Morin, J. C. Hope, and J. J. Loor. 2009a. Dietary-induced negative energy balance has minimal effects on innate immunity during a Streptococcus uberis mastitis challenge in dairy cows during midlactation. J. Dairy Sci. 92:4301-4316.

Moyes, K. M., N. C. Friggens, and K. L. Ingvartsen. 2010. Nutritional strategies to combat physiological imbalance of dairy cows during early lactation: The effect of changes in dietary protein and starch ratios. Acta Vet. Scand. A. 60:166-174.

Moyes, K. M., T. Larsen, N. C. Friggens, J. K. Drackley, and K. L. Ingvartsen. 2009b. Identification of potential markers in blood for the development of subclinical and clinical mastitis in dairy cattle at parturition and during early lactation. J. Dairy Sci. 92:5419-5428.

NRC. 2001. Nutrient Requirements of Dairy Cattle. National Academy Press, Washington, DC.

Nielsen, H. M., N. C. Friggens, P. Lovendahl, J. Jensen, and K. L. Ingvartsen. 2003. Influence of breed, parity, and stage of lactation on lactational performance and relationship between body fatness and live weight. Livest. Prod. Sci. 79:119-133.

Nielsen, N. I., N. C. Friggens, M. G. Chagunda, and K. L. Ingvartsen. 2005. Predicting risk of ketosis in dairy cows using in-line measurements of beta-hydroxybutyrate: A biological model. J. Dairy Sci. 88:2441-2453.

Ospina, P. A., D. V. Nydam, T. Stokol, and T. R. Overton. 2010. Evaluation of nonesterified fatty acids and beta-hydroxybutyrate in transition dairy cattle in the northeastern United States: Critical thresholds for prediction of clinical diseases. J. Dairy Sci. 93:546-554.

Sakha, M., M. Ameri, H. Sharifi, and I. Taheri. 2007. Bovine subclinical ketosis in dairy herds in Iran. Vet. Res. Commun. 31:673-679.

SAS Institute Inc. 2008. SAS User's Guide. Statistics Vol. 9, 2nd ed. Cary, NC.

Schoenberg, K. M., and T. R. Overton. 2011. Effects of plane of nutrition and 2,4-thiazolidinedione on insulin responses and adipose tissue gene expression in dairy cattle during late gestation. J. Dairy Sci. 94:6021-6035.

Schoenberg, K. M., K. L. Perfield, J. K. Farney, B. J. Bradford, Y. R. Boisclair, and T. R. Overton. 2011. Effects of prepartum 2,4-thiazolidinedione on insulin sensitivity, plasma concentrations of tumor necrosis factor-alpha and leptin, and adipose tissue gene expression. J. Dairy Sci. 94:5523-5532.

Seifi, H. A., S. J. LeBlanc, K. E. Leslie, and T. F. Duffield. 2011. Metabolic predictors of post-partum disease and culling risk in dairy cattle. Vet. J. 188:216-220.

Sigl, T., K. Gellrich, H. H. Meyer, M. Kaske, and S. Wiedemann. 2012. Multiparous cows categorized by milk protein concentration and energy-corrected milk yield during early lactation-Metabolism, productivity and effect of a short-term feed restriction. J. Anim. 
Physiol. Anim. Nutr. (Berl.) http://dx.doi.org/10.1111/j.14390396.2011.01268.x

Sjaunja, L. O., L. Baevre, L. Junkkarinen, J. Petersen, and J. Setala. 1990. A Nordic proposal for an energy corrected milk (ECM) formula. In 27th Bienn. Sess. Int. Comm. Anim. Rec. (ICAR). July 02-06. Pages 156-176 in EAAP - European Association for Animal Production Publication, vol. 50. Paris, France.

Stengärde, L., K. Holtenius, M. Traven, J. Hultgren, R. Niskanen, and U. Emanuelson. 2010. Blood profiles in dairy cows with displaced abomasum. J. Dairy Sci. 93:4691-4699.
Vernon, R. G. 2005. Lipid metabolism during lactation: A review of adipose tissue-liver interactions and the development of fatty liver. J. Dairy Res. 72:460-469.

Walsh, S. W., E. J. Williams, and A. C. Evans. 2011. A review of the causes of poor fertility in high milk producing dairy cows. Anim. Reprod. Sci. 123:127-138. 